\title{
STRUCTURAL PARAMETERS GOVERNING FATIGUE CRACKING IN HIGHWAY BRIDGES
}

\author{
By Ichiro OKURA*, Hiroyuki TAKIGAWA** and Yuhshi FUKUMOTO***
}

\begin{abstract}
In many plate girder highway bridges, fatigue cracks occur at the connections of cross beams to main girders. In this paper, the structural parameters governing the cracking at the cross-beam connections are presented. Then, the relationship between the parameters and the cracking at the cross-beam connections is investigated for the plate girder bridges on a route of the Hanshin Expressway in Osaka, and it is shown that the deformation of a concrete slab due to running vehicles has a great influence on the cracking at the cross-beam connections.

Keywords : fatigue, plate girder bridge, connection
\end{abstract}

\section{INTRODUCTION}

Fatigue cracks occur at the connections of cross beams to main girders in many plate girder highway bridges in the urban area of Japan. The fatigue cracks observed in the plate girder bridges of the Hanshin Expressway in Osaka are classified as shown in Fig. 1 according to the locations of cracking. Four types of cracks are initiated at the cross-beam connections. The investigation of the causes of the crack initiation and the development of repair methods have been under way at various research institutions. However, satisfactory results are not yet available.

In 1985, the authors carried out the field stress measurement of an existing plate girder bridge of the Hanshin Expressway to know the local stresses influential for the cracking at the cross-beam connections $^{1 / 2)}$. Later, they formulated the relationship between the local stresses and the threedimensional behavior of the bridge under traffic loading ${ }^{3)}$.

The objective of this paper is to clarify the qualitative relationship between the parameters introduced from the structural behavior of a plate girder bridge and the cracking at the cross-beam connections. First, the structural parameters affecting the cracking at cross-beam connections are deduced from the equations presented in Ref. 3). Then, the relationship between the structural parameters and the cracking at the cross-beam connections is investigated for the plate girder bridges on a route of the Hanshin Expressway.

* Member of JSCE, Dr. Eng., Assistant Professor, Department of Civil Engineering, Osaka University (Yamadaoka 2-1, Suita, Osaka 565)

** Member of JSCE, M. Eng., Nippon Steel Corporation, formerly Graduate Student, Department of Civil Engineering, Osaka University

*** Member of JSCE, Ph. D., Dr. Eng., Professor, Department of Civil Engineering, Osaka University 


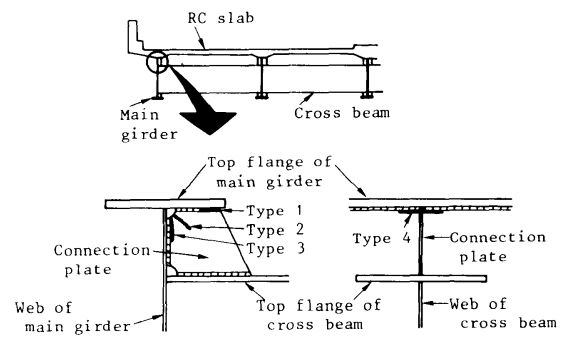

Fig. 1 Fatigue cracks at cross-beam connection of plate girder bridge.

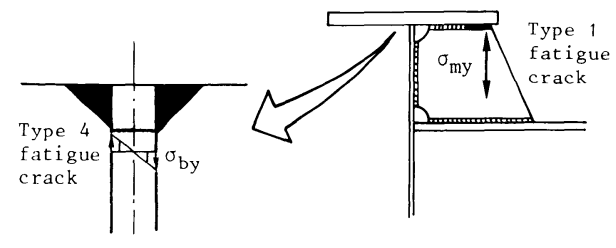

Fig. 2 Local stresses $\sigma_{m y}$ and $\sigma_{b y}$.

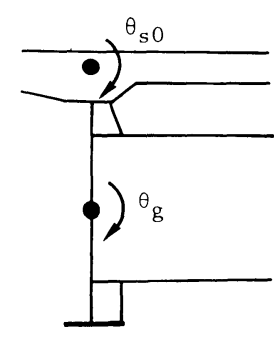

Fig. 3 Rotations $\theta_{s 0}$ and $\theta_{g}$.

\section{STRUCTURAL PARAMETERS AFFECTING CRACK INITIATION}

(1) Relationship between local stresses and rotations of concrete slab and of cross beam

As shown in Fig. 2, the membrane stress $\sigma_{m y}$ in the vertical direction on the connection plate and the plate-bending stress $\sigma_{b y}$ on the main girder web cause Types 1 and 4 fatigue cracks, respectively ${ }^{1,2)}$. The relationship between those local stresses and the rotations of concrete slab and of cross beam is given by ${ }^{3)}$

$$
\left[\begin{array}{c}
\sigma_{m y} \\
\sigma_{b y}
\end{array}\right]=\left[\begin{array}{cc}
k_{m 1} & k_{m 3}\left(\gamma-k_{m 123}\right) \\
k_{b 1} & k_{b 3}\left(\gamma-k_{b 123}\right)
\end{array}\right]\left[\begin{array}{c}
\theta_{s 0} \\
\theta_{g}
\end{array}\right]
$$

where $\theta_{s 0}=$ rotation of concrete slab due to the slab-deformation caused by wheel loads (see Fig. 3), $\theta_{g}=$ rotation of cross beam due to the vertical displacements of main girders (see Fig. 3), $\gamma=$ coefficient depending on the position of a vehicle in the direction of the roadway width, and $k_{m 1}, k_{m 3}, k_{m 123}, k_{b 1}, k_{b 3}$ and $k_{b 123}=$ constants which relate the local stresses to the rotations of concrete slab and of cross beam.

(2) Structural parameter for concrete-slab rotation

Referring to Fig. 4, the rotation $\theta_{s 0}$ of concrete slab at the position $(a, 0)$ where a main girder is located, is expressed by ${ }^{3)}$

$$
\theta_{s 0}=\frac{1}{2 \pi^{2}} \frac{a}{D_{c}}\left\{P \phi_{\rho}\left(\frac{x}{a}\right) \phi\left(\frac{x}{a}\right) \sum_{m=1}^{\infty} \frac{(-1)^{m}}{m^{2}} \sin \frac{m \pi x}{a}\left(1+\frac{m \pi|y|}{a}\right) \exp \left(-\frac{m \pi|y|}{a}\right)\right\}
$$

where $a=$ spacing between main girders, $D_{c}=$ flexural rigidity of concrete slab, $P=$ a concentrated load, $\phi_{p}(x / a)=$ correction factor for the wall parapets on the both sides of the roadway, and $\phi(x / a)=$ correction factor to treat the concrete slab as a continuous plate.

Eq. (2) expresses that the concrete-slab rotation $\theta_{s 0}$ varies with the values of $a / D_{c}$, even if the traffic conditions are the same. The values of $a / D_{c}$ can be determined by the dimensions of concrete slab. Hence, the reciprocal of $a / D_{c}$, namely, $D_{c} / a$ is chosen as a structural parameter for $\theta_{s 0}$. The plate girder bridges with the smaller values of $D_{c} / a$ are more susceptible to cracking, since the decrease of $D_{c} / a$ increases $\theta_{s 0}$ and then results in the increase of the local stresses of $\sigma_{m y}$ and $\sigma_{b y}$.

\section{(3) Structural parameters for cross-beam rotation}

Let us consider a plate girder bridge with five main girders shown in Fig. 5 . The rotation $\theta_{g i}$ of the cross beam at the main girder $G_{i}$ is given by the following equation ${ }^{3)}$ :

$$
\theta_{g_{i}}=\frac{1}{56 a} \boldsymbol{A}_{i} \boldsymbol{v}
$$

where $\boldsymbol{v}=\left(v_{1}, v_{2}, v_{3}, v_{4}, v_{5}\right)^{T}, v_{i}=$ vertical displacement of the girder $G_{i}$ at the cross-beam connection, $T$ $=$ symbol representing transpose, and $\boldsymbol{A}_{i}=i$-th row vector of the following $5 \times 5$ matrix :

$$
\left[\begin{array}{rrrrr}
-71 & 90 & -24 & 6 & -1 \\
-26 & -12 & 48 & -12 & 2 \\
7 & -42 & 0 & 42 & -7 \\
-2 & 12 & -48 & 12 & 26 \\
1 & -6 & 24 & -90 & 71
\end{array}\right]
$$




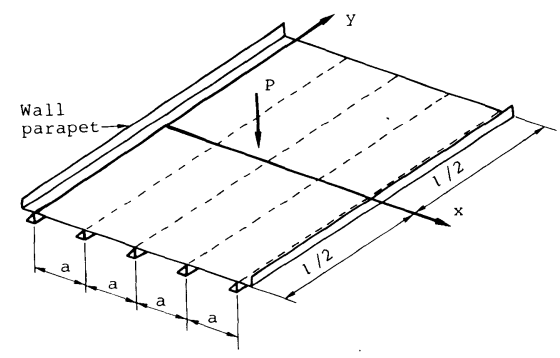

Fig. 4 Concrete slab under concentrated load $P$.

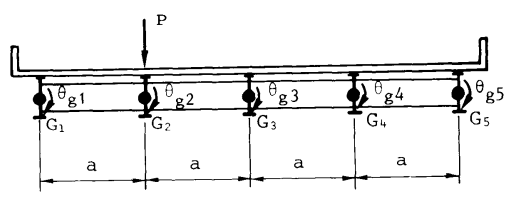

Fig. 5 Cross-beam rotation $\theta_{g_{i}}$.

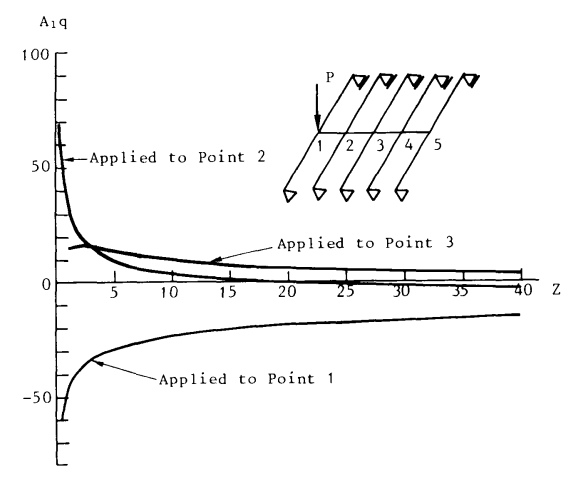

Fig. 6 Relationship between $A_{1} q$ and $Z$

When a concentrated load $P$ is applied to the girder $G_{j}$, the vertical displacement $v_{i}$ of the girder $G_{i}$ is provided with the following equation:

$$
v_{i}=\frac{P q_{i j} l^{3}}{48 E_{s} r_{i} I_{g}}
$$

where $q_{i j}=$ load-distribution-coefficient from the girder $G_{j}$ to $G_{i}, l=$ span length of main girders, $E_{s}=$ Young's modulus of steel, $r_{i}=I_{g i} / I_{g}, I_{g i}=$ moment-of-inertia of the main girder $G_{i}$, and $I_{g}=$ moment-ofinertia of any girder arbitrarily selected among five main girders.

The load-distribution-coefficient $q_{i j}$ is expressed by a function of $r_{i}$ and $Z$ defined by

$$
Z=\left(I_{Q} / I_{g}\right)\{l /(2 a)\}^{3} \text {. }
$$

where $I_{Q}=$ moment-of-inertia of a cross beam.

Substitution of Eq. (4) into Eq. (3) provides the following equation :

$$
\theta_{g_{i}}=P \frac{1}{2688 E_{s}} \frac{l^{3}}{a I_{g}} \boldsymbol{A}_{i} \boldsymbol{q}
$$

where $q=\left(q_{1 j} / r_{1}, \quad q_{2 j} / r_{2}, \quad q_{3 j} / r_{3}, \quad q_{4 j} / r_{4}, \quad q_{5 j} / r_{5}\right)^{T}$

Fig. 6 shows the relationship between $A_{1} q$ which corresponds to the cross-beam rotation $\theta_{g_{1}}$, and $Z$. The calculation of $\boldsymbol{A}_{1} \boldsymbol{q}$ is carried out for $r_{i}=1$. The formulae of $q_{i j}$ are given in Ref. 4). Except for the case of the concentrated load $P$ applied to the girder $G_{3}, A_{1} q$ is approximately inversely-proportional to $Z$ for $Z \leqq 10$. Accordingly, when $Z \leqq 10$, the term $\left\{l^{3} /\left(a I_{g}\right)\right\} A_{1} q$ in Eq. ( 6$)$ is proportional to $\left\{l^{3} /\left(a I_{g}\right)\right\} / Z$, and then considering Eq. $(5),\left\{l^{3} /\left(a I_{g}\right)\right\} / Z$ is changed into $8 a^{2} / I_{Q}$. On the other hand, when $Z>10$, only the term $\left\{l^{3} /\left(a I_{g}\right)\right\}$ is variable in Eq. (6), because $\boldsymbol{A}_{1} \boldsymbol{q}$ takes almost constant values for $Z>10$.

From the above discussion, the following structural parameters are chosen for the cross-beam rotation $\theta_{g_{i}}$ :

$$
\begin{aligned}
& I_{Q} / a^{2} \text { for } Z \leqq 10 \\
& a I_{g} / l^{3} \text { for } Z>10
\end{aligned}
$$

The plate girder bridges with the smaller values of these structural parameters are more susceptible to cracking, since the decrease of the parameters increases $\theta_{g}$ and then results in the increase of the local stresses of $\sigma_{m y}$ and $\sigma_{b y}$.

\section{RELATIONSHIP BETWEEN STRUCTURAL PARAMETERS AND CRACKING}

The relationship between $I_{Q} / a^{2}$ and initiation of Types 1 and 4 cracks is investigated for the plate girder 


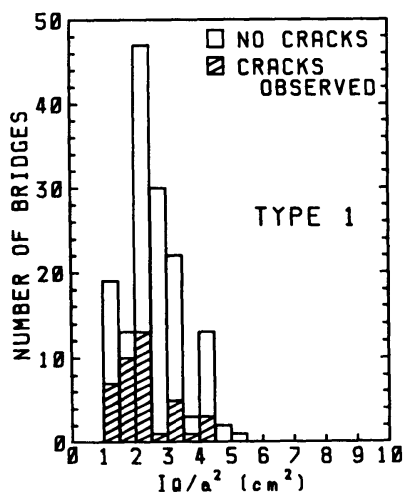

Fig. 7 Relationship between $I_{Q} / a^{2}$ and the number of bridges in which Type 1 cracks were observed

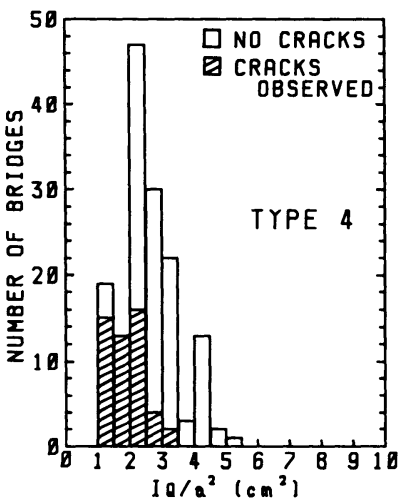

Fig. 8 Relationship between $I_{Q} / a^{2}$ and the number of bridges in which Type 4 cracks were observed

bridges on a route of the Hanshin Expressway). The value of $D_{c} / a$ is almost invariable on the route.

Fig. 7 shows the relationship between $I_{Q} / a^{2}$ and the number of bridges in which Type 1 cracks were detected. As pointed out in Ref. 5), the influence of $\theta_{g}$ on the local stress $\sigma_{m y}$ which causes Type 1 cracks is small in the plate girder bridge with $I_{Q} / a^{2}=3.1 \mathrm{~cm}^{2}$. In Fig. 7, however, Type 1 cracks occur in the bridges for $I_{Q} / a^{2} \geqq 3.0 \mathrm{~cm}^{2}$. This indicates that Type $1 \mathrm{cracks}$ can be initiated by the concrete-slab rotation only.

Fig. 8 shows the relationship between $I_{Q} / a^{2}$ and the number of bridges in which Type 4 cracks were detected. With the increase of $I_{Q} / a^{2}$, the number of the bridges suffering from cracking gradually decreases, because the influence of $\theta_{g}$ on the local stress $\sigma_{b y}$ which causes Type 4 cracks becomes small. No cracks occur in the bridges for $I_{Q} / a^{2} \geqq 3.5 \mathrm{~cm}^{2}$.

\section{CONCLUSIONS}

The structural parameters governing the fatigue cracking at the cross-beam connections of plate girder highway bridges are specified as follows according to the rotations of bridge components, that is to say, concrete slab and cross beam under vehicle loading:

a) For the concrete-slab rotation, $D_{c} / a$.

b) For the cross-beam rotation, $I_{Q} / a^{2}$ for $Z \leqq 10$, and $a I_{g} / l^{3}$ for $Z>10$.

The bridges are more susceptible to cracking, as the values of the above structural parameters become smaller. Type 1 cracks at the connection plates can be initiated by the concrete-slab rotation only.

\section{ACKNOWLEDGEMENTS}

The authors would like to thank Messrs. S. Uto and I. Nakamura, Hanshin Expressway Public Corporation, for the help with the data acquisition.

\section{REFERENCES}

1) Okura, I., Hirano, H. and Yubisui, M. : Stress measurement at cross beam connections of plate girder bridges, Technol. Repts. Osaka Univ., Vol. 37, No. 1883, pp. 151-160, 1987.

2) Okura, I. and Fukumoto, Y. : Fatigue of cross beam connections in steel bridges, IABSE, 13 th Congress, Helsinki, pp. 741-746, 1988.

3) Okura, I., Yubisui, M., Hirano, H. and Fukumoto, Y. : Local stresses at cross beam connections of plate girder bridges, Proc. of JSCE Struct. Eng. /Earthq. Eng., Vol.5, No. 1, pp. 89 s-97 s, Japan Society of Civil Engineers, 1988.

4) Watanabe, N. : Theory and Calculation of Grid Beams, Gihodo Publisher, Tokyo, pp. 44-45, 1965 (in Japanese).

5) Okura, I., Takigawa, H. and Fukumoto, Y. : Structural parameters governing fatigue cracking at cross-beam connections in plate girder highway bridges, Technol. Repts. Osaka Univ., Vol.39, No. 1980, pp. 289-296, 1989. 